\title{
Thermal Properties of Different Hat Fiber Contents for Baby
}

\author{
Cassandra Wentela \& Su Kyoung An \\ Central Michigan University
}

Keywords: thermal comfort, thermal Manikin, baby

When thinking of thermal properties and the body, we are often told to keep the head covered from early on. The Harvard Health Publishing (2012) mentions this idea because in cold weather the blood vessels at the surface of the head don't respond much to cold and also doesn't have fat for insulation. This results in the body losing body heat can be up to a $50 \%$ loss, if the head is not covered. With the head losing heat, this affects the rest of the body even if the wearer is covered everywhere else (Harvard Health Publishing, 2012).

Furthermore, the thermal properties of fibers and fabric content are important in understanding the interaction between garments and the body. Fan and Hunter (2009) listed general conclusions based on the effect fabrics have in terms of thermal properties. Some of which included thermal insulation increases when there are two fabrics, water content in fabrics lowers the thermal insulation, thermal properties increase when there is a second layer that is a fine woven fabric, when there is an increase in weight of fabric there is a small increase in insulation, and many more (Fan \& Hunter, 2009).

Knowing how important hats are for a baby, parents have to make sure their children always wear hats in cooler temperatures. Looking at a few mass-market retailers to see what fiber contents are often used for children hats, it can be seen Target often utilizes polyester and acrylic fiber contents. Kohl's offers a majority of acrylic and synthetic blends. Walmart offers a variety of fabrics such as polyester, nylon, wool, and acrylic. With there being a wide range of fabrics for children hats in the market as well as the research on thermal properties and importance of hats for kids, the researcher wanted to gain a better understanding of what fiber content is the best option for children hats. Thus, the purpose of this research is to determine what specific fiber content would be best for children to keep their head warm.

To test the thermal comfort level of different fiber content hats for baby, the dry thermal resistance $\left(\mathrm{R}_{\mathrm{ct}}\right)$ were collected by using a baby thermal manikin. The baby thermal manikin was created by Thermetrics and offers 11 zones. The Thermal Manikin was placed in a controlled environmental chamber as well as all tested garments for at least 12 hours according to ASTM standard 1291. Three hats were the focus of this study, the gold hat was $70 \%$ bamboo
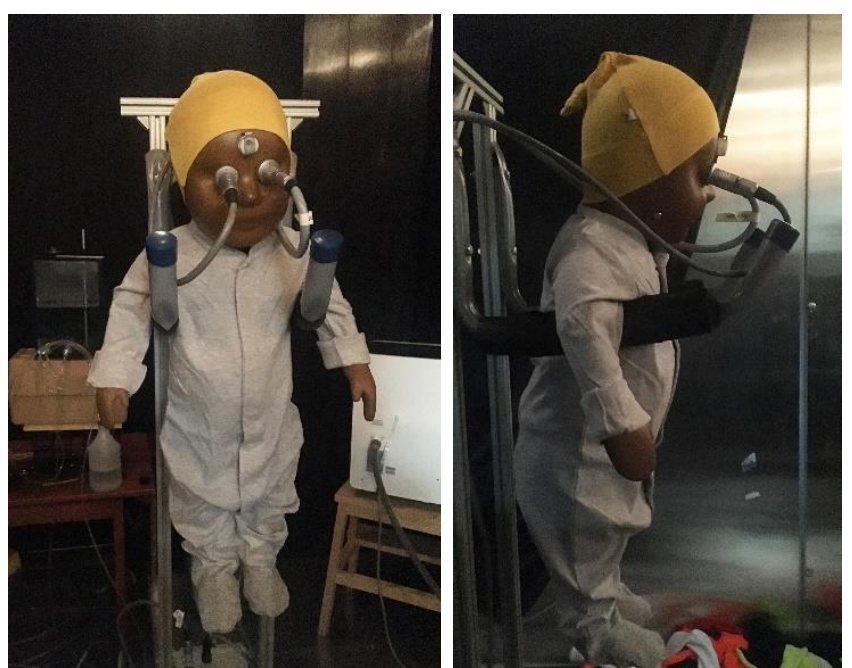

Figure 1. Baby Thermal Manikin wearing one of the hats and onesies used for testing.

Published under a Creative Commons Attribution License (https://creativecommons.org/licenses/by/4.0/), which permits unrestricted use, distribution, and reproduction in any medium, provided the original work is properly cited.

ITAA Proceedings, \#76 - https://itaaonline.org 
rayon and $30 \%$ cotton (BRC), the aqua hat was $100 \%$ cotton (C), and the grey hat was $97 \%$ bamboo rayon and 3\% spandex (BRS). The hat being the dependent variable, each hat was tested three times using ASTM standard 1291 with 12 hours conditioning in between tests along with the size 4 diaper and 100\% cotton onesies. There were three onesies that were used in order for each hat to have a 12-18 months onesie that was conditioned (Figure 1).

Table 1. ANOVA Table for Dry Thermal Resistance $\left(\mathrm{R}_{\mathrm{ct}}\right)$ by Fiber Content Hat Conditions

\begin{tabular}{ccccccc}
\hline & Source & Sum of Squares & df & Mean Square & F & Sig. \\
\hline \multirow{3}{*}{$\mathrm{R}_{\mathrm{ct}}$} & Between Groups & .000 & 2 & .000 & 3.667 & .091 \\
& Within Groups & .000 & 6 & .000 & & \\
& Total & .000 & 8 & & & \\
\hline
\end{tabular}

Analysis of variance (ANOVA) was run by using Statistical Package for the Social Sciences (SPSS) software to compare the $\mathrm{R}_{\mathrm{ct}}$ values among three different hats. In table 1, the results present no significant difference in $\mathrm{R}_{\mathrm{ct}}$ among the three different fiber content baby hats $\left(\mathrm{R}_{\mathrm{ct}}: \mathrm{F}(2,6=3.667, \mathrm{p}>.05)\right.$. It indicates that all different fiber content hats, BRC (mean $=.0756), \mathrm{C}($ mean $=.0793)$, and $\mathrm{BRS}($ mean $=$ .0793 ), possess similar levels of dry thermal resistance. Therefore, there is no significant difference in terms of heat insulation for the different fiber contents.

Thus, any fiber content is a viable option for thermal comfort for a child. For future studies, testing different fiber contents via hotplate and then constructing the hats to all look the same would be helpful. There was difficulty finding hats already made that were the same exact style and same exact fit yet different fiber contents. For very cold temperatures where a thin hat will not be enough, a second layer would be beneficial. A future study would be beneficial in determining if there is a specific fiber content that would be as the second layer in correspondence with the desired base layer.

\section{References:}

Fan, J., \& Hunter, L. (2009). Engineering apparel fabrics and garments. Elsevier.

Harvard Health Publishing. (2012, February). Cold out? Why you need to wear a hat! Retrieved from https://www.health.harvard.edu/staying-healthy/cold-out-why-you-need-to-wear-a-ha

Kaufman, W., Bothe, D., \& Meyer, S. (1982).Thermal insulating capabilities of outdoor clothing materials. Science (New York, N.Y), 215 (4533), 690-691.

Page 2 of 2

Published under a Creative Commons Attribution License (https://creativecommons.org/licenses/by/4.0/), which permits unrestricted use, distribution, and reproduction in any medium, provided the original work is properly cited.

ITAA Proceedings, \#76 - https://itaaonline.org 